\title{
Lactancia materna y postnatal, un desafío de país
}

\author{
FRANCISCO MORAGA M. ${ }^{1}$ \\ 1. Profesor Asociado Universidad de Chile, Subjefe Servicio de Pediatría, Hospital San Borja Arriarán. \\ Presidente, Sociedad Chilena de Pediatría.
}

La inminente promulgación del proyecto de ley sobre extensión del reposo postnatal y la discusión establecida en torno a la promoción de la lactancia incluida en el proyecto de ley sobre composición nutricional de alimentos y su publicidad, ha dado inicio a un giro trascendental en las políticas públicas que contribuirá a mejorar la calidad de vida de miles de niños y madres de nuestro país, ya que transforma en hechos concretos el compromiso, contraído por el Estado chileno desde hace varios años, en reconocer, promover y defender derechos básicos del recién nacido e involucrar a ambos padres en el proceso de crianza, iniciando el pago de una deuda histórica que tenemos para con los derechos de los niños y adolescentes.

Los avances en el conocimiento de las propiedades de la leche humana y del vínculo entre el recién nacido y su madre, han modificado considerablemente la apreciación del rol trascendente de la relación entre la madre y el lactante. Entre los avances que nos muestra la investigación, está la observación de que cuando se realiza el acto de amamantamiento se produce la liberación de muchas hormonas, tanto en la madre como en el lactante; algunas adaptan el intestino neonatal para optimizar la absorción de nutrientes, otras preparan la maduración de muchos de sus órganos y sistemas, otras facilitan la recuperación de la madre y finalmente, otras determinan y facilitan los vitales procesos de apego. Otros hallazgos demuestran que el recién nacido sano, colocado sobre el pecho de su madre, es capaz de recuperar o mantener la temperatura corporal eficientemente y que en contacto con la piel de su madre se tranquiliza y es capaz de arrastrarse gradualmente hacia el pecho materno e iniciar la succión por sus propios medios. Estas características han evolucionado genéticamente desde hace más de 400000 años para preservar la vida del lactante, ya que demostradamente contribuyen a promover el apego y reducir las tasas de abandono.

Si a todos estos hechos clínicos se agrega el conocimiento actual de la enorme variedad de biofactores presentes en la leche humana, el rol fundamental de sus ácidos grasos para el desarrollo cerebral, su efecto programador sobre el metabolismo y la expresión génica, el efecto protector frente a una serie de problemas de salud en edades precoces que se proyectan a futuro como las condicionantes de salud que conforman la mayor parte de la carga de salud del adulto, sólo podemos concluir que el privar de lactancia a un recién nacido le confiere una serie de desventajas y vulnerabilidades que es deber del equipo de salud evitar, tomando un rol activo en la promoción y preservación de la lactancia, ya no sólo como una fuente de nutrientes, sino como una de las formas de actuar concordante con la evolución de la especie al contribuir a asegurar condiciones de desarrollo humano óptimos.

En esta línea, la SOCHIPE generó el año 2001 la Declaración del Congreso Chileno de

Correspondencia a:

Dr. Francisco Moraga M.

E-mail: fjmoraga@gmail.com 
Pediatría de Pucón (Rev Chil Pediatr 2002; 73: 197) donde sentó las bases del proyecto de ley titulado "Prolongación de la Licencia Postnatal a Seis Meses, para proteger el Apego y Lactancia Natural” entregado en la Oficina de Partes del Congreso Nacional el año 2002, documento previamente conocido y aprobado por la Comisión de Salud de la Cámara de Diputados, y ha impulsado permanentemente esta iniciativa mediante numerosas acciones tales como la elaboración de un documento técnico respecto de la relación costo-efectividad de su implantación, manteniendo conversaciones con los productores y distribuidores de sucedáneos de la leche materna en un afán de hacer cumplir los principios del Código OMS sobre comercialización ética de estos productos, ha suscrito editoriales respecto a estos tópicos, convocando a los medios y participando en reuniones de trabajo con representantes de ambas cámaras del Poder Legislativo, Ministerio de Salud, Comisión Nacional de Lactancia, Colegios de Matronas, de Nutricionistas Universitarias y Colegio Médico, UNICEF, etc., reforzando permanentemente estos contenidos en las actividades académicas que desarrolla y, actualmente, participando en la discusión sobre el Proyecto de Ley "Composición nutricional de los alimentos y su publicidad" promoviendo en su articulado la incorporación con fuerza de ley, del Código OMS de comercialización de sucedáneos de la leche materna.

Hasta aquí, esta es la visión como pediatras y sociedad científica dedicada a contribuir a la salud infantil. Sin embargo, no podemos desconocer que existen otros puntos de vista, tan legítimos como el defendido desde la ciencia, que expresan sus reparos a la iniciativa de la extensión del postnatal hasta los seis meses. Sin pretender ser exhaustivo, destaco sólo algunos: ¿Es justo traspasarle exclusivamente a la mujer la responsabilidad del establecimiento de un apego saludable, o éste debe ser visto como una responsabilidad compartida con su pareja y con protección del Estado?, es decir ¿no podría transformarse en una trampa legal para la mujer dejarle exclusivamente la responsabilidad de la salud mental infantil, en un país con altas tasas de problemas en ésta área, y así dejar ahora por decreto, los asuntos de los niños como uno de índole privada, en vez de ser un tema de responsabilidad de Estado, como debiera ser?.

Pero aún esto puede tener otras aristas. Hoy la mujer ha demostrado su capacidad de ejercer responsabilidades directivas y asumir liderazgos de todo tipo. ¿Estarán dispuestos los empleadores a contratar a una mujer en edad fértil sabiendo que si se embaraza se alejará legalmente del trabajo por 224 días, es decir, trabajará en el mejor de los casos el $40 \%$ de un año?. Es posible que una empresa o empleador de cualquier giro quiera evitar contratar a profesionales calificadas en puestos directivos claves, si no va a tener seguridad de su continuidad para liderar programas o proyectos. Así, en el campo laboral, la mujer en edad fértil podría quedar en inferioridad de condiciones para optar a cargos a causa de un postnatal prolongado, por lo que parece importante que la discusión parlamentaria en este tema, permita sentar las bases para una agenda de medidas complementarias e integrales que permitan perfeccionar y facilitar la inserción laboral femenina, como por ejemplo subsidios a la contratación de mujeres en edad fértil y especialmente de los segmentos sociales más vulnerables de la sociedad chilena, así como políticas de sensibilización en empleadores y a la sociedad en general respecto de la importancia de la extensión del postnatal y el efecto que esto produce en el desarrollo de nuevas y mejores generaciones de niños.

También está la mirada desde el punto de vista económico. El subsidio postnatal es aportado y financiado directamente por el Estado; en este caso, las aseguradoras recibirán la totalidad del plan de salud por los seis meses que se propone, período en que el costo para éstas se reduciría considerablemente por la menor morbilidad del niño favorecida por la lactancia y no asistencia a sala cuna: menor expendio de bonos de atención, cobertura de exámenes, procedimientos y eventuales hospitalizaciones, así como por menor enfermedad materna debido a depresión puerperal, ¿¿Se traducirá este beneficio para las aseguradoras en menor costo para la trabajadora? ¿Deben las aseguradoras contribuir al financiamiento de esta iniciativa, ya que obtendrían beneficios directos?. 
Relacionado a este último aspecto, está el tema de la equidad. Lo normal es que los subsidios del Estado sean progresivos, es decir, que entreguen más beneficios a quienes tienen mayor vulnerabilidad. En el caso de la extensión del postnatal, éste subsidio llegaría principalmente a los deciles de mayores ingresos, ya que en los deciles de menos ingresos sólo un $28 \%$ de las mujeres se encuentra cotizando, en cambio, en el caso de las mujeres del décimo decil, el 87\% cotiza. ¿Cómo se transforma éste en un subsidio no regresivo?. La ecuación debe incluir la rentabilidad social que genera esta extensión del postnatal, extensamente tratado en el documento de Aedo (Rev Chil Pediatr 2007, vol.78, suppl.1: 10-50).

Prolongar el postnatal es el más hermoso regalo que se le puede hacer al recién nacido, a su madre y a la sociedad. Todos los médicos sabemos que el concepto de apego se desarrolla y cultiva con el contacto permanente, pero esto es necesario conciliarlo con nuestras propias realidades de país en desarrollo. Como Sociedad Chilena de Pediatría somos la voz de los niños y responsables de aportar lo que la evidencia científica nos ofrece para orientar en la toma de decisiones que el Estado ha decidido asumir en éste ámbito y garantes de hacer cumplir la visión del niño como sujeto de Derecho. Sin embargo, no desconocemos que hay otras miradas, legitimadas por otros intereses, que deben estar contempladas en el instrumento legal definitivo, de manera que se vean reflejados los distintos intereses y se transforme en un instrumento efectivo y no efectista, unificador y no disociador, de consensos en vez de imposiciones.

Nuestro país tiene la madurez política y social que permita hacer de la protección a la infancia un compromiso de Estado, fruto de un amplio debate, entre las distintas instancias sociales, debate en el que la SOCHIPE será siempre la voz de los derechos de los niños.

\section{A LOS AUTORES}

Comunicamos a los autores de los artículos presentados para publicación en Revista Chilena de Pediatría, que ha concluido exitosamente el Proyecto Editorial del Fondo de Publicación de Revistas Científicas CONICYT 2008-2009 "Revista Chilena de Pediatría: De las Publicaciones en Papel a un Proceso Editorial On-Line basado en Open Journal System". Por lo tanto, solicitamos a los autores de los artículos presentados a partir de ahora, que ingresen a www.revistachilenadepediatria.cl, se registren e identifiquen de acuerdo a las instrucciones, y procedan a ingresar su contribución al sistema editorial electrónico según se detalla.

La Sociedad Chilena de Pediatria y Revista Chilena de Pediatría se enorgullecen de poner a disposición de nuestros colaboradores esta moderna herramienta editorial, en forma pionera entre las publicaciones biomédicas de nuestro país.

El Editor 